\title{
Influence of chronic kidney disease on the effectiveness of cardiac rehabilitation in patients after cardiac surgery
}

\author{
IWONA ROTTER ${ }^{1, A, D, G}$, ALICJA MIŃKO ${ }^{2, D-F}$, ZUZANNA HILICKA ${ }^{2, \text { D-F }}$, DOMINIK TURZYŃSKI' D-F, \\ ORCID ID: 0000-0002-4337-6476 'ORCID ID: 0000-0003-2299-3958 'ORCID ID: 0000-0001-8137-8555 ORCID ID: 0000-0003-2486-0032

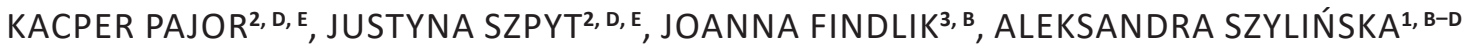 \\ ORCID ID: 0000-0002-7280-3254 ORCID ID: 0000-0003-1686-069X ORCID ID: 0000-0002-6318-1342 ORCID ID: 0000-0001-6105-5329
${ }^{1}$ Department of Medical Rehabilitation and Clinical Physiotherapy, Pomeranian Medical University, Szczecin, Poland ${ }^{2}$ Students' Science Club "Kinezis" of the Department of Medical Rehabilitation and Clinical Physiotherapy, Pomeranian Medical University, Szczecin, Poland
${ }^{3}$ Cardiac Rehabilitation Department, University Hospital No. 2 of the Pomeranian Medical University, Szczecin, Poland

A - Study Design, B - Data Collection, C - Statistical Analysis, D - Data Interpretation, E - Manuscript Preparation, F - Literature Search, $\mathbf{G}$ - Funds Collection

Summary Background. Patients with Chronic Kidney Disease (CKD), with an additional burden of cardiovascular disease, should be monitored, educated and treated through the close cooperation between multidisciplinary nephrology and cardiology teams. One of the elements by which this can be achieved is cardiac rehabilitation programs.

Objectives. The aim of this study is to assess the effect of chronic kidney disease on exercise performance within cardiac patients. Material and methods. 92 patients qualified for stationary cardiac rehabilitation took part in a study conducted at the Cardiac Surgery Clinic of the SPSK 2 Pomeranian Medical University in Szczecin. Among them, a group with CKD $(n=24)$ and without $(n=68)$ was selected. Statistical analysis was performed on the basis of data from medical records and the results of the 6-minute walk test. Results. Patients with and without CKD improved the results of the 6 -minute test. From an average result of $256.21( \pm 138.99)$ at the beginning of the rehabilitation to an average of 385.96 ( \pm 109.09) after that for patients with CKD and from average result of 281.01 $( \pm 110.16)$ to an average result of 422.29 ( \pm 96.39$)$ for patients without CKD.

Conclusions. Cardiac rehabilitation has a positive effect on physical fitness and exercise tolerance both in patients with CKD and without. However, the coexistence of CKD results in less satisfactory results compared to the control group.

Key words: cardiac rehabilitation, cardiology, kidney diseases, walk test.

Rotter I, Mińko A, Hilicka Z, Turzyński D, Pajor K, Szpyt J, Findlik J, Szylińska A. Influence of chronic kidney disease on the effectiveness of cardiac rehabilitation in patients after cardiac surgery. Fam Med Prim Care Rev 2021; 23(4): 470-474, doi: https://doi.org/10.5114/ fmpcr.2021.110365.

\section{Background}

Chronic kidney disease (CKD), according to the Kidney Disease Outcome Quality Initiative (KDOQI) guidelines, is defined as impaired renal function characterized by reduced estimated Glomerular Filtration Rate (eGFR) or markers of kidney damage, or both, for at least three months. Chronic kidney disease is a serious health problem due to its high morbidity and mortality [1-3]. In addition, there is a high risk of cardiovascular complications. CKD occurs in $4.5 \%$ of the general population, while within patients with heart failure with preserved or reduced ejection fraction, the rate increases to $50 \%$. Among cardiac patients, the frequency of this disease may also be burdened with additional risk factors, such as hypertension, age, low ventricular ejection fraction and low hemoglobin levels $[4,5]$. It is associated with metabolic and systemic disorders in the circulatory system caused by impaired renal function. Moreover, the developing systemic inflammation and endothelial dysfunction may lead to stiffening of the cardiomyocytes, hypertrophy and interstitial fibrosis $[6,7]$.

The risk of cardiovascular diseases within people with CKD is also associated with uremia, oxidative stress and abnormal calcium and phosphorus metabolism [8]. The presence of chronic kidney disease is associated with an increased risk of cardiovascular and non-cardiovascular mortality within patients with heart failure. The risk of death in the presence of these disease entities is double [9-11]. The effect of kidney disease on exercise capacity is not well understood. Renal dysfunction may act as an enhancer of sympathetic activation in heart failure while enhancing the sympathetic, central and peripheral mechanisms underlying decreased exercise capacity $[1,12,13]$. Moreover, chronic metabolic acidosis may exacerbate catabolic or anabolic disorders in skeletal muscles, and high levels of angiotensin II may intensify protein degradation and myocyte apoptosis, ultimately leading to skeletal myopathy. Hormonal disorders, oxidative stress and uremic toxins may also contribute to reduced physical capacity. Patients with chronic kidney disease and with an additional burden of cardiovascular disease should be monitored, educated and treated through close collaboration between multidisciplinary nephrology and cardiology teams. One of the mechanisms by which this can be achieved is cardiac rehabilitation programs $[1,14,15]$.

\section{Objectives}

The aim of this study is to assess the effect of chronic kidney disease on exercise performance within cardiac patients.

\section{Material and methods}

The retrospective study, which was conducted at the SPSK2 Cardiac Surgery Clinic of the Pomeranian Medical University 
in Szczecin, was attended by 92 people. They underwent cardiac surgery and were then qualified for cardiac rehabilitation in a stationary facility in the period from March to December 2019. The criteria of exclusion from participation in cardiac rehabilitation included: incomplete medical documentation and contraindications for cardiac rehabilitation.

24 patients with chronic disease participated in the study. Among them, 23 patients also suffered from heart failure (95.83\%), 16 from arterial hypertension (66.67\%), 7 from arrhythmias (29.17\%) and 3 patients from COPD (12.50\%). Among the subjects with chronic disease there were, 20 men (83.33\%) and 4 women (16.67\%). 12 patients (50\%) underwent CABG, 2 patients $(8.33 \%)$ underwent combined CABG, 8 patients $(33.33 \%)$ underwent valve surgery, and 2 patients $(8.33 \%)$ underwent aneurysm surgery. Moreover, 3 people with chronic disease declared themselves smokers.

The second study group consisted of 68 patients without chronic kidney disease. There was 48 men (70.59\%) and 20 women (29.41\%). 40 patients (58.82\%) underwent CABG surgery, 13 patients (19.12\%) underwent complex CABG, 9 patients (13.24\%) underwent valve surgery, 4 patients $(5.88 \%)$ underwent aneurysm surgery, and 2 (2.94\%) underwent minimally invasive procedures. 11 patients were identified as smokers. In the group without chronic kidney disease, 57 people suffered from heart failure (83.82\%), 58 people from hypertension (85.30\%), 12 patients from arrhythmias (17.65\%) and 4 from COPD (5.88\%).

Medical records provided information on the diagnosis, comorbidities, Creatinine $(\mathrm{Cr})$ and Glomerular Filtration Rate (GFR). In addition to using data provided by medical records, the study used a 6-minute walk test to measure physical performance. Each patient was tested on the first day of admission to the rehabilitation ward and on the last day of rehabilitation at discharge. Blood pressure and heart rate were also checked during the test.

\section{6-minute walk test}

To prepare for the test, you must initially sit for 10 minutes. The task of the participant in the study is to then walk around the designated area (30 meters) of the rehabilitation ward room at their own pace. Before and after the trial, the patient's heart rate and blood pressure are measured. In the event of a clinical disorder, such as breathlessness, pallor of the complexion, balance disorder or pain sensation, the test is interrupted and repeated once the clinical state is stable.

\section{Cardiac rehabilitation}

Cardiac rehabilitation is a complex and comprehensive form of patient care, which consists of many different strategies. Patients stay in the ward for 3 to 4 weeks. The most commonly used technique to improve the patient's condition include hand patting, performed once a day for 3 to 5 minutes in the morning. Additionally, breathing techniques are performed using the
Triflo apparatus. Patients breathe in and out 3 times deeply in 2 series with intervals of 1 minute. They do this once an hour. Moreover, once a day, group gymnastics is conducted, consisting of active general development exercises. Depending on the patient's clinical condition, resistance exercises are gradually introduced every other day. The recommended load is $50-60 \%$ of the maximum muscle strength. Exercises are performed in 5 series of 5 repetitions with a break of 30 to 60 seconds. Exercise intensity should be at a level of 2-3 points according to the modified Borg scale. The relaxation exercises performed at the beginning and end of group exercise are breathing exercises with the use of different respiratory ways: upper-chest, lower-chest and diaphragmatic. An important element of rehabilitation is medically controlled training on a cycloergometer, the parameters of which are determined on the basis of an exercise test performed on admission to the rehabilitation department. The intensity of training on a cycloergometer should not exceed 3 points according to the modified Borg scale. In addition, patients perform anticoagulation exercises - active movements in the wrist and ankle joints vigorously at a rate of about 16 movements per minute for a period of 5 minutes. This operation is repeated every half hour throughout the day. In their spare time, it is also recommended to walk at a moderate pace and use the exercise rotors, the recommended use of which is 3 times a day for 10 minutes.

\section{Statistics}

Statistical analysis was carried out using a licensed RStudio program. For this purpose, the Shapiro-Wilk test, $t$-Test, Mann-Whitney $U$ test, Chi-square test or its variance with the test correction were used. Tests were used to evaluate the quantitative distribution of data and present quantitative data as mean, standard deviation and median. A $p$-value of $\leq 0.05$ turned out to be statistically significant.

\section{Ethics and permissions}

The study was conducted in accordance with the standards of the Helsinki Declaration and was approved by the Bioethics Committee of the Pomeranian Medical University (decision no. KB-0012/84/12/2020/Z).

\section{Results}

The results of the characteristics of the examined people depending on the incidence of chronic kidney disease are presented in Table 1.

The mean result of the 6-minute test performed on the first day of rehabilitation in the group of patients with CKD was $256.21 \mathrm{~m}( \pm 138.98)$, while in the control group, it was 281.01 $\mathrm{m}( \pm 110.16)$. Re-performance of the test on the last day of stay at the ward showed the same results: $385.96 \mathrm{~m}$ ( \pm 109.09) and $422.29 \mathrm{~m} \mathrm{(} \pm 96.39)$. Accordingly, both groups of patients ob-

\begin{tabular}{|c|c|c|c|c|}
\hline & & without CKD $(n=68)$ & with CKD $(n=24)$ & $p$ \\
\hline \multicolumn{5}{|c|}{ Demographic data } \\
\hline \multicolumn{2}{|c|}{ Age [years] (mean \pm SD; Me) } & $69.46 \pm 6.71 ; 69.00$ & $70.79 \pm 14.82 ; 73.00$ & 0.102 \\
\hline \multirow[t]{2}{*}{ Gender ( $n, \%)$} & male & $48(70.59 \%)$ & $20(83.33 \%)$ & \multirow[t]{2}{*}{0.341} \\
\hline & female & $20(29.41 \%)$ & $4(26.67 \%)$ & \\
\hline \multirow[t]{3}{*}{$\operatorname{BMI}(n, \%)$} & norm & $16(20.78 \%)$ & $6(27.27 \%)$ & \multirow[t]{3}{*}{0.739} \\
\hline & overweight & 38 (49.35\%) & 9 (40.91.38\%) & \\
\hline & obesity & $23(29.87 \%)$ & $7(31.82 \%)$ & \\
\hline \multicolumn{2}{|c|}{$\mathrm{BMI}($ mean \pm SD; Me) } & $28.07 \pm 4.51 ; 28.04$ & $28.31 \pm 4.64 ; 27.55$ & 0.98 \\
\hline \multicolumn{2}{|l|}{ Smoking $(n, \%)$} & $11(16.18 \%)$ & $3(12.50 \%)$ & 0.94 \\
\hline
\end{tabular}




\begin{tabular}{|l|l|l|l|}
\hline \multicolumn{3}{|l|}{ Table 1. Demographic and disease data and selected parameters in patients with and without CKD } & $p$ \\
\hline & without CKD $(n=68)$ & with CKD $(n=24)$ & \\
\hline Disease data & & & 0.20 \\
\hline Heart failure $(n, \%)$ & $57(83.82)$ & $23(95.83 \%)$ & 0.117 \\
\hline Hypertension $(n, \%)$ & $58(85.30 \%)$ & $16(66.67 \%)$ & 0.348 \\
\hline Cardiac rhythm disturbances $(n, \%)$ & $12(17.65 \%)$ & $7(29.17 \%)$ & 0.533 \\
\hline COPD $(n, \%)$ & $4(5.88 \%)$ & $3(12.50 \%)$ & \\
\hline Other parameters & & & $<0.001$ \\
\hline GFR (mean \pm SD; Me) & $77.18 \pm 14.38 ; 76.50$ & $51.67 \pm 18.78 ; 51.00$ & $<0.001$ \\
\hline Creatinine (mean \pm SD; Me) & $0.94 \pm 0.21 ; 0.09$ & $1.46 \pm 0.62 ; 1.31$ & \\
\hline
\end{tabular}

$n$-number of patients, $p$-statistical significance, $S D$ - standard deviation, Me - median, $\mathrm{BMI}$ - body mass index $\left(\mathrm{kg} / \mathrm{m}^{2}\right)$, COPD - chronic obstructive pulmonary disease, GFR - glomerular filtration rate.

\begin{tabular}{|c|c|c|c|c|}
\hline & & \multirow{2}{*}{$\begin{array}{l}\text { without CKD }(n=68) \\
\text { mean } \pm \text { SD; Me }\end{array}$} & \multirow{2}{*}{$\begin{array}{l}\text { with CKD }(n=24) \\
\text { mean } \pm \text { SD; Me } \\
\end{array}$} & \multirow[t]{2}{*}{$p$} \\
\hline & & & & \\
\hline \multicolumn{2}{|c|}{ First 6-MWT distance [m] } & $281.01 \pm 110.16 ; 302.50$ & $256.21 \pm 138.99 ; 285.00$ & 0.499 \\
\hline \multirow[t]{2}{*}{ Systolic pressure } & before & $127.30 \pm 14.32 ; 130.00$ & $124.83 \pm 12.91 ; 123.50$ & 0.349 \\
\hline & after & $135.37 \pm 25.04 ; 137.00$ & $137.96 \pm 20.47 ; 138.00$ & 0.836 \\
\hline \multicolumn{2}{|c|}{ Difference of systolic pressure } & $11.66 \pm 16.46 ; 10.00$ & $13.13 \pm 14.44 ; 10.50$ & 0.752 \\
\hline \multirow[t]{2}{*}{ Diastolic pressure } & before & $73.51 \pm 9.46 ; 73.00$ & $73.63 \pm 13.25 ; 75.50$ & 0.968 \\
\hline & after & $75.74 \pm 10.17 ; 74.00$ & $75.04 \pm 13.98 ; 77.50$ & 0.824 \\
\hline \multicolumn{2}{|c|}{ Difference of diastolic pressure } & $2.82 \pm 7.94 ; 3.00$ & $1.42 \pm 9.05 ; 2.00$ & 0.574 \\
\hline \multirow[t]{2}{*}{ Heart rate } & before & $79.40 \pm 12.02 ; 82.00$ & $75.29 \pm 8.18 ; 72.00$ & 0.069 \\
\hline & after & $88.47 \pm 13.81 ; 90.50$ & $83.79 \pm 12.09 ; 83.50$ & 0.124 \\
\hline \multicolumn{2}{|c|}{ Difference of heart rate } & $9.09 \pm 10.86 ; 7.00$ & $8.50 \pm 9.18 ; 8.50$ & 0.728 \\
\hline \multicolumn{2}{|c|}{ Last 6-MWT distance [m] } & $422.29 \pm 96.39 ; 440.00$ & $385.96 \pm 109.09 ; 407.00$ & 0.010 \\
\hline \multirow[t]{2}{*}{ Systolic pressure } & before & $123.65 \pm 13.59 ; 123.50$ & $122.13 \pm 16.86 ; 121.00$ & 0.658 \\
\hline & after & $139.32 \pm 18.13 ; 140.50$ & $142.61 \pm 23.60 ; 143.00$ & 0.547 \\
\hline \multicolumn{2}{|c|}{ Difference of systolic pressure } & $16.41 \pm 13.95 ; 18.00$ & $20.04 \pm 19.45 ; 24.00$ & 0.415 \\
\hline \multirow[t]{2}{*}{ Diastolic pressure } & before & $67.84 \pm 10.07 ; 67.50$ & $70.39 \pm 11.54 ; 70.00$ & 0.351 \\
\hline & after & $70.52 \pm 10.30 ; 70.00$ & $78.00 \pm 15.49 ; 78.00$ & 0.040 \\
\hline \multicolumn{2}{|c|}{ Difference of diastolic pressure } & $2.68 \pm 10.63 ; 4.00$ & $7.61 \pm 10.82 ; 5.00$ & 0.275 \\
\hline \multirow[t]{2}{*}{ Heart rate } & before & $70.01 \pm 9.95 ; 68.00$ & $73.74 \pm 12.63 ; 72.00$ & 0.298 \\
\hline & after & $77.76 \pm 11.01 ; 76.00$ & $83.30 \pm 17.26 ; 81.00$ & 0.277 \\
\hline \multicolumn{2}{|c|}{ Difference of heart rate } & $7.75 \pm 7.66 ; 9.00$ & $9.57 \pm 10.97 ; 10.00$ & 0.680 \\
\hline \multicolumn{2}{|c|}{ Difference of 6-MWT distance [m] } & $135.24 \pm 83.12 ; 121.00$ & $132.96 \pm 83.29 ; 110.00$ & 0.952 \\
\hline
\end{tabular}

$n$ - number of patients, $p$-statistical significance, SD - standard deviation, Me - median, 6-MWT-6 Minute Walk Test, CKD - chronic kidney disease.

tained a higher test result after the rehabilitation cycle; however, those without CKD showed greater improvement $(p=0.010)$. The results, along with the analysis of systolic and diastolic pressure, as well as the heart rate measured before and after comprehensive cardiac rehabilitation, are presented in Table 2.

The mean result of the 6-minute test performed on the first day of rehabilitation in the group of patients with CKD was $256.21 \mathrm{~m}( \pm 138.98)$, while in the control group, it was 281.01 $\mathrm{m}( \pm 110.16)$. Re-performance of the test on the last day of stay

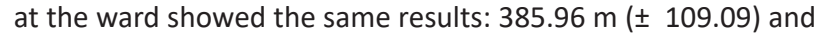
$422.29 \mathrm{~m}( \pm 96.39)$. Accordingly, both groups of patients obtained a higher test result after the rehabilitation cycle; howev$\mathrm{er}$, those without CKD showed greater improvement $(p=0.010)$. The results, along with the analysis of systolic and diastolic pressure, as well as the heart rate measured before and after comprehensive cardiac rehabilitation, are presented in Table 2 .

Statistical analysis showed that people without CKD had a higher heart rate before the 6-minute walk test on admission in relation to people with CKD $(p=0.069)$. The mean value for them was $79.40( \pm 12.02)$, while in patients with chronic kidney disease, it was 75.29 ( \pm 8.18$)$.
According to the results, on the day of discharge, patients without CKD obtained a lower diastolic blood pressure value of $70.52( \pm 10.30)$ after the 6 -minute test $( \pm 10.30)$ compared to those with CKD $(78.00( \pm 15.49))$. The studied dependence showed a value of $p=0.04$

\section{Discussion}

The study investigated the influence of chronic kidney disease on exercise performance in patients after cardiosurgical incidents. The research tool used in the study was a 6-minute walk test with heart rate and pressure measurements. It is a safe, simple and repeatable test, thanks to which it is possible to assess the functional state of the patient. It also allows one to measure the progress of physiotherapy in subsequent stages $[16,17]$.

In our study, it was found that patients without chronic kidney disease $(p=0.010)$ obtained a better result in the test after rehabilitation with an average result of $422.29 \mathrm{~m}( \pm 96.39)$ 
in comparison to the result of 385.96 ( \pm 109.09) obtained by people suffering from this disease.

The study by Hama et al. involved 86 people with cardiovascular diseases and coexisting chronic kidney disease who participated in 3-month cardiac rehabilitation. The mean age of the patients was 74 years, and the majority of the subjects were male (70.9\%). The aim of the study was to determine the impact of cardiac rehabilitation on the condition of patients with chronic kidney disease, as well as on kidney function. The rehabilitation program included motor therapy and nutrition and medication education. Movement exercises included aerobic techniques with the use of ergometers and resistance techniques. Another of the patients' tasks was to walk for a certain amount of time. Moreover, on admission to rehabilitation and after its completion, the patients performed an exercise test on an ergometer. During the exercise, blood pressure and ECG were measured. The measurement of serum creatinine and serum cystatin- $C$ was used to assess renal function. The study proved that cardiac rehabilitation significantly improves functional capacity and kidney function. Moreover, the measurement of serum cystatin- $C$ levels may help in determining renal function in people with cardiovascular diseases and chronic kidney disease [18].

A study aimed at assessing the impact of chronic kidney disease on the level of physical exertion during cardiac rehabilitation in patients with coronary artery disease was conducted by Pflum et al. 805 patients enrolled in a 12-week cardiac rehabilitation program were analyzed. Training sessions were held 3 times a week and lasted about 30-40 minutes. Each of these included exercises for both the upper and lower parts of the body. Parameters such as height, weight, systolic and diastolic blood pressure and heart rate were recorded at each visit. The exercises performed by the patients were: walking on walks within the hospital ward, exercises on a bicycle ergometer and treadmill and climbing stairs. Metabolic Equivalent (MET) levels were recorded during each session and were obtained automatically from exercise devices or by using a standardized and validated MET formula from the American College of Sports Medicine. According to the statistical analysis, the MET value of each patient improved after the entire rehabilitation cycle. All subjects achieved a statistically significant improvement in exercise capacity, quality of life and body weight, regardless of the base- line GFR, but the greatest increase in exercise performance was seen in patients with baseline GFR $\geq 60 \mathrm{ml} / \mathrm{min} / 1.73 \mathrm{~m}^{2}$ [19].

Takaya et al. conducted studies aimed at assessing the impact of cardiac rehabilitation on kidney function in patients after a myocardial infarction. 528 patients who took part in a 3-month rehabilitation program were qualified. According to the statistical analysis, it was shown that in patients with chronic kidney disease, the eGFR improved after the entire exercise cycle $(48$ \pm 12 to $53 \pm 15 \mathrm{ml} / \mathrm{min}^{-1} 1.73 \mathrm{~m}^{-2}, p<0.001$ ), along with the improvement in peak $\mathrm{VO}^{2}[20]$.

Qiu et al., in their meta-analysis to evaluate the health effects of exercise in patients with chronic renal failure, showed that an exercise program including warm-up, strength and aerobic exercise improves blood pressure in patients and improves maximum oxygen consumption. The results of subgroup analysis indicated that physical activity can significantly reduce blood pressure in patients with renal failure, as well as significantly reduce $\mathrm{VO}^{2}$ in patients with renal failure [21].

The findings of this study have to be taken in light of some limitations. The study was conducted to determine the effect of chronic kidney disease on exercise performance within cardiac patients, as the researchers wished to check if this kind of disease has a significant impact on recovery and rehabilitation. The first limitation was incomplete medical records due, which consequently reduced the study group. The second limitation concerned patients being subjected to various types of treatment, which is not without consequences in terms of how quickly the patient will recover. Another issue worth noting is that in the control group, there were patients with various comorbidities, which also affects the subjective perception of the results.

During further research, the list of respondents can be expanded thanks to cooperation with other centers where cardiosurgical operations are performed.

\section{Conclusions}

Comprehensive cardiac rehabilitation had a positive effect on the improvement of physical fitness parameters, both in patients with chronic kidney disease and without. However, improvements were found to a greater extent in patients without CKD, which shows that chronic kidney disease has an impact on exercise capacity and exercise tolerance in patients after cardiac surgery.

Source of funding: This work was funded from the authors' own resources.

Conflicts of interest: The authors declare no conflicts of interest.

\section{References}

1. Tedeschi A, Agostoni P, Pezzuto B, et al. Role of comorbidities in heart failure prognosis Part 2: Chronic kidney disease, elevated serum uric acid. Eur J Prev Cardiol 2020; 27: 35-45, doi: 10.1177/2047487320957793.

2. Gentille Lorente DI, Salvadó Usach T. Frequency of kidney failure in cardiologic patients: the need to search. Rev Med Chil 2015; 143(9): 1105-1113, doi: 10.4067/S0034-98872015000900002.

3. House AA, Wanner C, Sarnak MJ, et al. Heart failure in chronic kidney disease: conclusions from a Kidney Disease: Improving Global Outcomes (KDIGO) Controversies Conference. Kidney Int 2019; 95(6): 1304-1317, doi: 10.1016/j.kint.2019.02.022.

4. Villanego F, Naranjo J, Vigara LA, et. al. Impact of physical exercise in patients with chronic kidney disease: sistematic review and metaanalysis. Nefrologia 2020; 40(3): 237-252, doi: 10.1016/j.nefro.2020.01.002.

5. Wilkinson TJ, Shur NF, Smith AC. “Exercise as medicine" in chronic kidney disease. Scand J Med Sci Sports 2016; 26(8): 985-988, doi: $10.1111 /$ sms.12714.

6. Uhlinova J, Pechter U, Põlluste K, et. al. Patient-reported outcomes: association between physical activity and quality of life in patients with chronic kidney disease. Fam Med Prim Care Rev 2020; 22(4): 343-348, doi: 10.5114/fmpcr.2020.100448.

7. Ter Maaten JM, Damman K, Verhaar MC, et al. Connecting heart failure with preserved ejection fraction and renal dysfunction: the role of endothelial dysfunction and inflammation. Eur J Heart Fail 2016; 18(6): 588-98, doi: 10.1002/ejhf.497.

8. Sarnak MJ, Amann K, Bangalore S, et al. Chronic kidney disease and coronary artery disease: JACC State-of-the-Art Review. J Am Coll Cardiol 2019; 74(14): 1823-1838, doi: 10.1016/j.jacc.2019.08.1017.

9. Weaver DJ, Mitsnefes M. Cardiovascular disease in children and adolescents with chronic kidney disease. Semin Nephrol 2018; 38(6): 559-569, doi: 10.1016/j.semnephrol.2018.08.002.

10. Kent S, Schlackow I, Lozano-Kühne J, et. al. What is the impact of chronic kidney disease stage and cardiovascular disease on the annual cost of hospital care in moderate-to-severe kidney disease? BMC Nephrol 2015; 16: 65, doi: 10.1186/s12882-015-0054-0.

11. Howden EJ, Coombes JS, Isbel NM. The role of exercise training in the management of chronic kidney disease. Curr Opin Nephrol Hypertens 2015; 24(6): 480-487, doi: 10.1097/MNH.0000000000000165. 
12. Calvo-Lobo C, Neyra-Bohorquez PP, Seco-Calvo J. Aerobic exercise effects in renal function and quality of life of patients with advanced chronic kidney disease. Rev Assoc Med Bras 2019; 65(5): 657-662, doi: 10.1590/1806-9282.65.5.657.

13. Howden EJ, Coombes JS, Strand H, et. al. Exercise training in CKD: efficacy, adherence, and safety. Am J Kidney Dis 2015; 65(4): 583-591, doi: 10.1053/j.ajkd.2014.09.017.

14. Müller-Ortiz H, Pedreros-Rosales C, Vera-Calzaretta A, et. al. Entrenamiento físico en personas con enfermedad renal crónica avanzada: beneficios de su implementación en la práctica clínica. Rev Med Chil 2019; 147(11): 1443-1448, doi: 10.4067/S003498872019001101443 (in Spanish).

15. Pei G, Tang Y, Tan L, et al. Aerobic exercise in adults with chronic kidney disease (CKD): a meta-analysis. Int Urol Nephrol 2019; 51(10): 1787-1795.

16. Du H, Wonggom P, Tongpeth J, et. al. Six-minute walk test for assessing physical functional capacity in chronic heart failure. Curr Heart Fail Rep 2017; 14(3): 158-166, doi: 10.1007/s11897-017-0330-3.

17. Uszko-Lencer NHMK, Mesquita R, Janssen E, et. al. Reliability, construct validity and determinants of 6-minute walk test performance in patients with chronic heart failure. Int J Cardiol 2017; 240: 285-290, doi: 10.1016/j.ijcard.2017.02.109.

18. Hama T, Oikawa K, Ushijima A, et al. Effect of cardiac rehabilitation on the renal function in chronic kidney disease - Analysis using serum cystatin-C based glomerular filtration rate. IJC Heart \& Vasculature 2018; 19: 27-33, doi: 10.1016/j.ijcha.2018.04.001.

19. Pflum A, Gomadam P, Mehta H, et al. Effect of chronic kidney disease and supplemental polyunsaturated fatty acid use on exercise levels during cardiac rehabilitation in patients with coronary artery disease. J Cardiopulm Rehabil Prev 2017; 37(3): 199-206, doi: 10.1097/HCR.0000000000000197.

20. Takaya Y, Kumasaka R, Arakawa T, et al. Impact of cardiac rehabilitation on renal function in patients with and without chronic kidney disease after acute myocardial infarction. Circ J 2014; 78(2): 377-384, doi: 10.1253/circj.cj-13-0779.

21. Qiu Z, Zheng K, Zhang H, et. al. Physical exercise and patients with chronic renal failure: a meta-analysis. Biomed Res Int $2017 ; 7191826$. doi: 10.1155/2017/7191826.

Tables: 2

Figures: 0

References: 21

Received: 10.02.2021

Reviewed: 07.03.2021

Accepted: 25.04.2021

Address for correspondence:

Zuzanna Hilicka

Studenckie Koło Naukowe „Kinezis”

przy Zakładzie Rehabilitacji Medycznej i Fizjoterapii Klinicznej

Pomorski Uniwersytet Medyczny w Szczecinie

ul. Żołnierska 54

70-204 Szczecin

Polska

Tel.: +48 509-455-319

E-mail: hilickaz@gmail.com 